\title{
PSYCHE
}

$\begin{array}{lll}\text { Vol. } 76 & \text { June, } 1969 & \text { No. } 2\end{array}$

\section{A REVISION OF THE NEOTROPICAL DACETINE ANT GENUS ACANTHOGNATHUS (HYMENOPTERA: FORMICIDAE}

\author{
By William L. Brown, Jr. ${ }^{1}$ and Walter W. KempF ${ }^{2}$
}

\section{INTRODUCTION}

At the time it was last reviewed (by M. R. Smith in 1944), Acanthognathus contained three species: ocellatus, lentus and brevicornis, known from Central America and a few localities along the eastern edge of South America. In the present paper we are able to add three distinctive new species-one from the heart of Amazonia, one from the Pacific Slope of Colombia, and one from Southeastern Brasil; and a male of the genus is described for the first time. We present fragmentary observations on living colonies of $A$. rudis and $A$. ocellatus to confirm M. R. Smith's surmise that the genus is predaceous, at least to some extent on Collembola.

Acanthognathus is a very distinctive genus within the tribe Dacetini, to which it clearly belongs, and within which it is one of the two most primitive living genera (Brown and Wilson, 1959). The other primitive member is Daceton, containing a single spectacular species confined to hylaean South America (Wilson, 1962). Though Daceton and Acanthognathus workers share a number of primitive characters (antennal segments II; palpal segments 5, 3; compound eyes large; antennal scrobes absent; humeri armed), they are very different in size, habitus, and choice of nest site, and thus may have diverged a long time ago. Acanthognathus has the aspect of a genus that has begun a shift from epigaeic to cryptic foraging. Its retention of large eyes, multisegmented antennae and palpi, and long mandibles suggests that much of its foraging must still be done in the open,

\footnotetext{
${ }^{1}$ Department of Entomology and Limnology, New York State College of Agriculture at Cornell University, Ithaca, New York 14850, USA.

${ }^{2}$ Convento de São Francisco, Caixa Postal 5,650, São Paulo, S. P., Brasil. Manuscript received by the editor January 2, 1969
} 

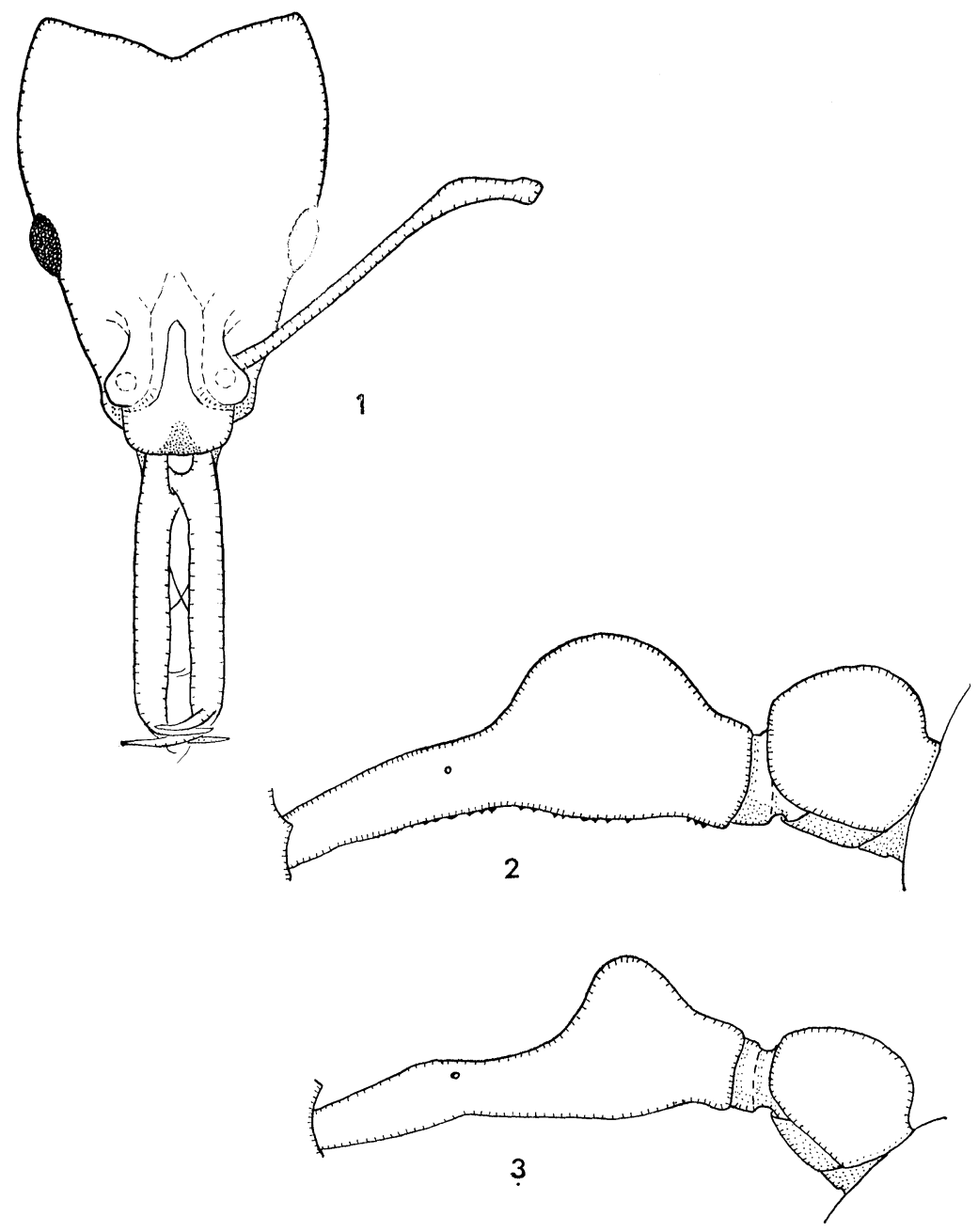

Figures 1-3. Acanthognathus spp., workers from type series in outline, sculpture and most pilosity omitted. Fig. 1, A. rudis sp. n. from type locality (Jardim Botanico, Agua Funda, São Paulo), dorsal view of head and mandibles. Fig. 2, $A$. rudis (Guararema, São Paulo), petiole and postpetiole from side. Fig. 3, A. stipulosus sp. n., holotype petiole and postpetiole in side view. Fig. 1 drawn by Brown, Figs. 2 and 3 by Kempf and Brown. 
even though its nests tend to be cryptically situated in the ground or rotten wood. Like most or all Orectognathus, the related Australian genus, its species probably forage mainly at night.

\section{Acanthognathus}

Acanthognathus Mayr, 1887:578. Type species Acanthognathus ocellatus, monobasic.

Acanthognathus: Emery, 1922, Gen. Insect., 174c:317-318.- M. R. Smith, 1944:150-152, key to spp.- Brown, 1948:125, in generic key.- Brown and Wilson, $1959: 281-283$, phylogeny, biology.

Worker: Size small (TL 3.5-4.6 mm). Habitus of strumigeniform Dacetini, i.e., with head much longer than broad, more or less depressed dorsoventrally, and much narrowed and drawn out anteriad, with a deep posterior excision (Figs. I, II); mandibles greatly elongate, narrow and linear, straight or nearly so, each with 3 spiniform apical teeth. Somewhat beyond the midlength of each mandible, there is often a small welt or convexity on the inner margin, whence issues a long, fine hair, the trigger hair, which lies flat against the margin when the mandible is closed, but which stands erect when the mandible is open, pointing straight forward, and serving as a tactile range-finder. Preapical teeth or denticles also occur on the mandibles of some species. Near the base of each mandible a long, slender basal process arises from its ventral surface and runs obliquely basoventrad, crossing its opposite number when the mandibles are closed (Fig. I) ; the apices of these processes are split into a pair of short acute teeth, by means of which they engage one another when serving as props to hold the mandibles widely open. (The basal processes have also been observed by Moeller and ourselves to be used in carrying brood in rudis and ocellatus, with mandibles opened widely.)

Frontal lobes form small convex shields over the antennal insertions. Eyes large, near or slightly in front of middle of sides of head, only moderately convex, normally with 40 to 70 or more facets. Clypeus narrowly bell-shaped, flat, with long posterior lobe inserted between frontal lobes. Antennae long and slender, IIsegmented (Figs. I,4,II), with the scapes oddly bent and usually constricted near apex. Small antennal segments III through IX in a rigid straight line, and may sometimes be fused internally, corresponding (as Santschi has already pointed out) to the long segment III in the Australasian genus Orectognathus. Antennal scrobes lacking. Occipital area deeply and broadly concave, set off from vertex by a sharply rounded angle. 
Maxilla with 5, labium with 3 segments in each palpus. Labrum reduced to a small piece shaped like an inverted $\mathrm{V}$.

Truncus strongly constricted and deeply impressed at metanotal groove; pro- and mesonotum fused together; humeral angles distinct and often more or less toothlike. Propodeum armed with a pair of slender oblique spines; declivity flat or weakly concave, smooth, at most feebly carinate on sides; inferior propodeal plates small, subacutely angled to rounded; propodeal spiracles circular, situated close under the bases of the spines, directed posterolaterad; atrum of metapleural gland with dark borders visible through integument, large, elliptical, oblique. Petiole with a long, slender, anteriorly tapered peduncle in front, a distinct, at least discally smooth and shining node, and a short posterior peduncle (Figs. 2-4). Postpetiole rounded, not very different in width from petiolar node, smooth and shining, at least on summit. No spongiform tissues on nodes or elsewhere. Gaster broadly oval, smooth and shining. Legs long and slender, femora moderately incrassate in apical half; no spurs on middle and posterior tibiae; claws slender, simple. Sting slender, rigid, with very acute tip; exsertile, functional.

Sculpture ranging from almost entirely smooth and shining (teledectus) to rugulose and opaque over dorsum of head and truncus (rudis), with at least some coarse but shallow, round tuberculate fossae on the head, and often a few on promesonotum as well. The tubercles of these fossae often each bear a single, short, slender, curved or reclinate clavate hair, these clavate hairs also more or less generally distributed over scapes, mandibles, femora and tibiae, promesonotum, propodeal spines, posterodorsal faces of both nodes, and sometimes underside of head. Short fine erect or reclinate hairs on mandibular apices, funiculi of antennae, tarsi and gastric apex; gastric dorsum also with very sparse, fine, short appressed hairs. Color prevailingly ferruginous.

Queen: Similar to worker in size and proportions, but with 3 ocelli, larger compound eyes, and the usual differences due to the prenuptial presence of well-developed wings and thoracic flight sclerites. Scutellum prominent and convex, propodeal spines welldeveloped and acute, but stouter than in worker.

Male (known only for $A$. rudis, Figs. 5-IO): Habitus dacetine, but slender; node long and low; sculpture mostly smooth and shining with fine punctures. Mandibles reduced to minute rounded lobes, each with a single acute tooth; separated by labrum, which is larger than mandibles and has a lobe at each free corner, just above the 


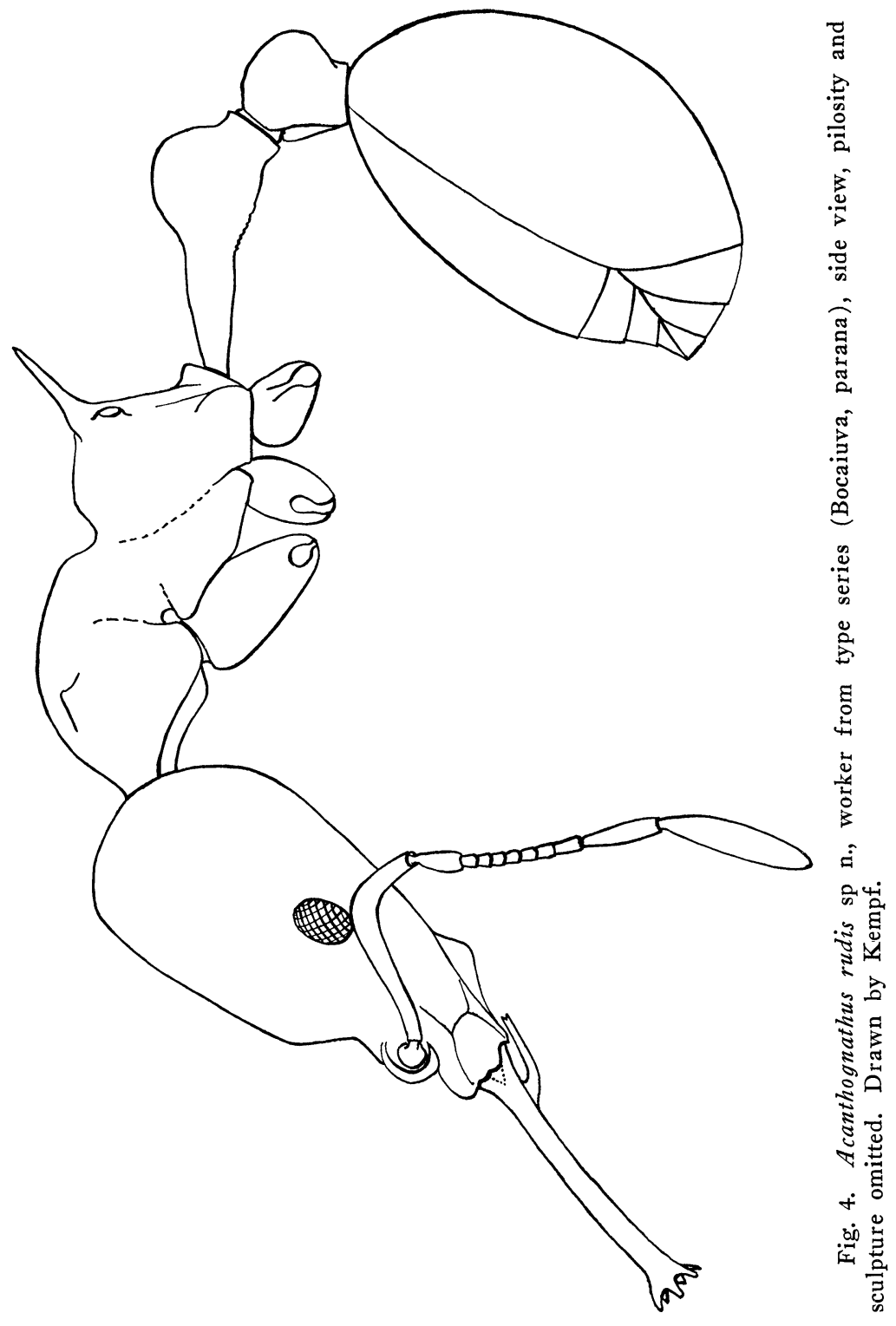


slightly projecting, single-segmented labial palpi. Maxillary palpi not seen in undissected mouth-parts, presumably reduced to a single small segment. Antennae long, I2-segmented; scape and pedicel subequal in length, each about twice as long as broad; flagellum filiform, only very slightly thicker at apex than at base. Compound eyes large and strongly convex, placed near the front of the sides and occupying about half the sides. Ocelli prominent, raised, surrounding a prominent indentation in the vertex.

Truncus well-developed, mesonotum with weak parapsidal furrows and notauli, the latter incomplete, not or at least not distinctly fused behind. Pronotum and propodeum unarmed, rounded; inferior propodeal plates present.

Wings long, densely microtrichiate; apical margin of fore wing and apical and hind margins of hind wing with a wide fringe of fine hairs.

Legs slender, long; tarsal claws simple, short, fine; tibiae of middle and hind legs without apical spurs.

Genitalia (Figs. 8-IO) formed on the same plan as Strumigenys; aedeagus valves subtruncate apically, cuspis of volsella slender; mesal face of paramere broadly excavated opposite volsella. Hypopygium elongate-triangular, with concave sides tapering to a narrowly rounded apex.

Pilosity abundant and widely distributed, consisting of short, fine soft brown hairs, mostly decumbent, but erect on propodeum. Color dark brown to probably blackish in fully-colored specimens; appendages pale.

Larva: To be described separately by G. C. and J. Wheeler.

\section{Distribution, Ecology and Behavior}

As now known from definite records, Acanthognathus ranges from Honduras in the north to Rio Grande do Sul in the south. It seems very likely that its range reaches into northeastern Argentina and to Bolivia, and it would not be surprising to find the genus in southern Mexico. Two of the new species described here extend the records into the Amazonian heartland and to Trans-Andean Colombia, while a new collection of $A$. ocellatus is the first for the genus from Trinidad.

The great increase in collections of Acanthognathus in recent years is due in large part to the rise in use of the Berlese funnel and similar methods of extraction of forest soil and litter, as well as to more intensive collecting in rotting twigs and similar microhabitats on the 
floor of tropical forests. All of the samples for which we have ecological data came from moist or wet forest of the tropical or subtropical type. Nests of isolated (possibly nest-founding) dealate queens of brevicornis, lentus, ocellatus and rudis have usually been taken in rotten twigs or small pieces of rotting wood in forest litter. The colonies are small, often with only IO-20 or fewer adult workers, and no nests with more than about 30 workers have been seen. Usually there is a single dealate queen per nest, though two have been found in a nest of $A$. rudis from São Paulo. The nests resemble greatly those of certain long-mandibulate Strumigenys, as already noted by Mann (I922), and like Strumigenys, the Acanthognathus workers and queen move slowly and often curl up to play dead when jarred.

An observation of Moeller, repeated by Emery (I922) and others, showed that workers use the basal processes of the mandibles to carry their brood. We have been able to confirm this activity for $A$. ocellatus and $A$. rudis in captive colonies. We have also observed these same two species to capture, by means of a snap of the mandibles, entomobryid Collembola that were placed in the artificial nest with them. A colony of $A$. ocellatus from Cerro Campana, Panama, fed a newly-captured entomobryid to a larva, after the fashion of Strumigenys. Limited tests of other small, soft-bodied arthropods were tried with both ocellatus and rudis, and though none of these was captured or even approached, the trials were too few to establish the breadth of prey specificity. Foraging workers of these two species, and the holotype of $A$. teledectus before its capture in the leaf litter, held their mandibles open to about $180^{\circ}$ when threatened or when approaching prey. This is apparently accomplished by locking together the apices of the opposed basal processes, but the details are not altogether clear, especially the role, if any, of the labrum in the process. As with Strumigenys, the sting is employed to quiet struggling prey.

A worker of $A$. ocellatus taken by Markl on Trinidad is accompanied by the note, "at night," indicating what the relatively large eyes suggest - that foraging is epigaeic, perhaps subarboreal, and largely crepuscular or even nocturnal. The similar Australasian genus Orectognathus appears to follow this foraging pattern.

\section{The Species}

Acanthognathus comprises six known species, of which five are very distinct, and one, $A$. lentus, is kept separate from $A$. ocellatus with doubt for the time being. 
The descriptions and measurements (Table I) utilize some abbreviations kept standard in recent works on ants, particularly the tribe Dacetini. HL is the length of the head in full-face (dorsal) view, including occipital lobes and the entire clypeus. $\mathrm{HW}$ is the maximum measurable width of the head in full-face view. CI is cephalic index, or $\mathrm{HW} / \mathrm{HL} \times$ Ioo. $\mathrm{ML}$ is the exposed length of the closed mandibles beyond clypeal margin, measured in full-face view. SL is the chord length of the antennal scape; SI (scape index) is $\mathrm{SL} / \mathrm{HW} \times$ Iоo. $\mathrm{MI}$ is the mandibulo-cephalic index, or $\mathrm{ML} / \mathrm{HL}$ $\times$ roo. SMI, scape-mandibular index, is SL/ML $\times$ roo. All measurements are in millimeters, and have an approximate error of \pm O.OI $\mathrm{mm}$.

Abbreviations for the main collections in which deposit has been made are: ( $\mathrm{MCZ}$ ) Museum of Comparative Zoology, Harvard University, Cambridge, Massachusetts 02138, USA; (USNM) United States National Museum, Washington, D. C. 20560, USA; (WWK) Collection of W. W. Kempf, including the Collection of Thomas Borgmeier, Caixa Postal 5,650, São Paulo, S. P., Brasil; (DZSP) Departamento de Zoologia, Caixa Postal 7 172, São Paulo, Brasil. Other collections are given in full. The species are listed in alphabetical order.

\section{Acanthognathus brevicornis}

Acanthognathus brevicornis M. R. Smith, 1944: 150-152, worker, dealate queen. Type loc.; Barro Colorado Island, Panama Canal Zone. Holotype worker and paratype queen in USNM; paratype queens in MCZ.- Kempf, 1964:67, worker from Nova Petropolis, Rio Grande do Sul, Brasil.

Worker and queen: Distinguishable from the similar A. ocellatus (see below) by 2 main characters:

I. Scapes shorter than those of other species of the same size; scape length (chord) about equal to head width in the worker, less in the queen (see Table I). Scape length markedly less than mandible length in both worker and queen; all other species have scapes as long as or longer than mandibles, except $A$. teledectus with its extraordinarily long mandibles.

2. Mandibles (o.86 $\mathrm{mm}$ long in holotype worker, teste Smith) with noticeable submedian welt on inner borders and 2-5 irregular, separated low denticles or minute tubercles in the space between the welt and the apical teeth on each mandible. No other species has these denticles so far as known.

In addition, the sculpture of $A$. brevicornis is more strongly effaced, more shining than in $A$. ocellatus, but not as much so as in $A$. 
teledectus. The brevicornis fossae on head and alitrunk tend to be smaller, shallower and more widely spaced, with interspaces correspondingly broader, smoother and more shining.

Male unknown.

Material examined (in addition to type series- I worker and 3 queens from Panama Canal Zone): BRASIL: State of Rio Grande do Sul: Nova Petropolis, September 1959, F. Plaumann leg., I worker (WWK); Morro Reuter, December 1964, F. Plaumann leg., I dealate queen (WWK). State of Pará: Utinga Forest Tract, near Belém, 9 August 1962, P. F. Darlington leg., dealate queen from hollow rotten twig on rain forest floor (MCZ).

\section{Acanthognathus lentus}

Acanthognathus lentus Mann, 1922:34-35, fig. 16, worker, queen. Type loc.: Progreso, Honduras. Syntypes in MCZ, USNM, WWK.

Worker and queen: Measurements and proportions given in Table I, closely overlapping those of $A$. ocellatus, fossae of dorsum of head larger and more crowded, with some rugulae present between them even on the posterior half, weakly shining; extreme posterior corners of cephalic dorsum smooth and shining. Otherwise very similar to $A$. ocellatus.

$A$. lentus probably is only a local sculptural variant of $A$. ocellatus. The scanty material available does not yet wholly bridge the difference, but a Trinidad specimen of ocellatus (q.v.) shows a tendency to do so.

Male unknown.

Mann's description is sketchy, and there is apparently a confusing deletion of several lines coming near the middle of the last printed line on his p. 34. His artist's figure is also not very faithful in portraying mandibular apices and head sculpture.

Material examined: Only a few workers from the type series, collected by Mann in rotten wood (MCZ, USNM).

\section{Acanthognathus ocellatus}

Acanthognathus ocellatus Mayr, 1887: 579, worker. Type loc.: Brasil, "St. Catharina."- Mann, 1916: 452, pl. 5, "fig. 38" (recte 39), queen, from Belém, Pará, Brasil.- M. R. Smith, 1944: 150, in key. Type worker currently in Museo Civico di Storia Naturale, Genoa, Italy, but properly belongs in Naturhistorisches Museum, Vienna, Austria; not seen by authors (discussed below).

Worker: If there is an "average" or "typical" member of the genus, this is it. Head more convex dorsally than in A. rudis; posterior excision in full-face view evenly semicircular (rather than 


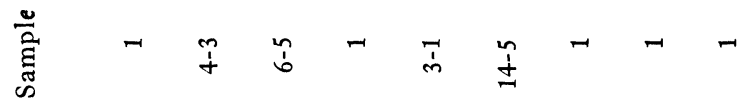

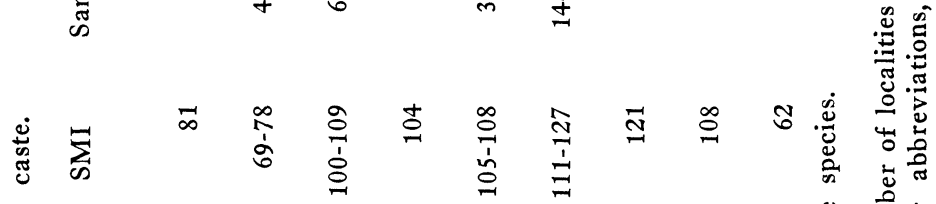

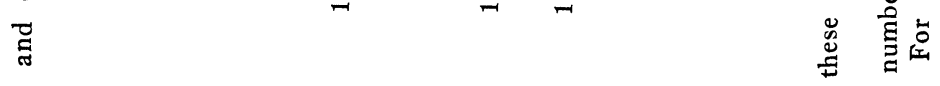

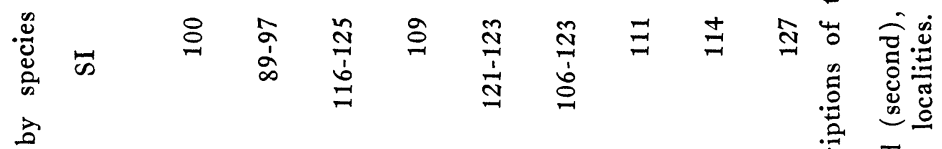

$$
\begin{aligned}
& \text { s. } \\
& \text { 穿 }
\end{aligned}
$$

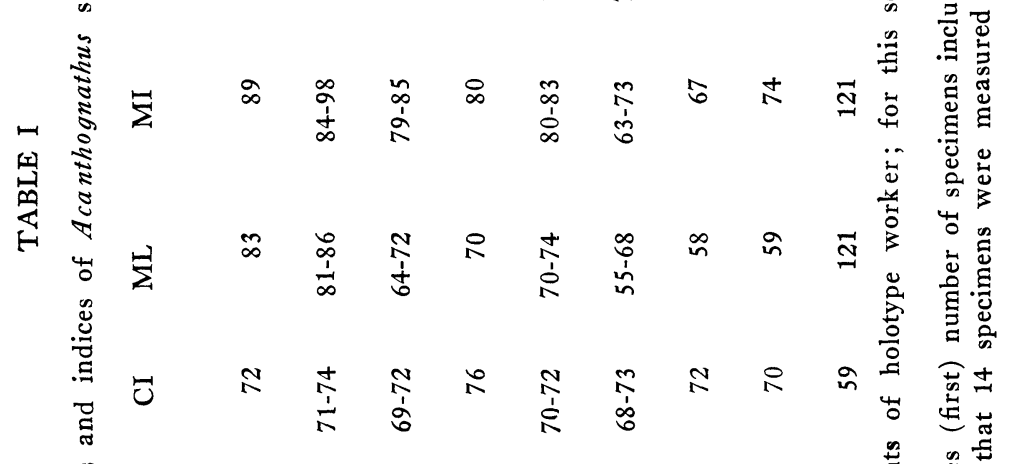

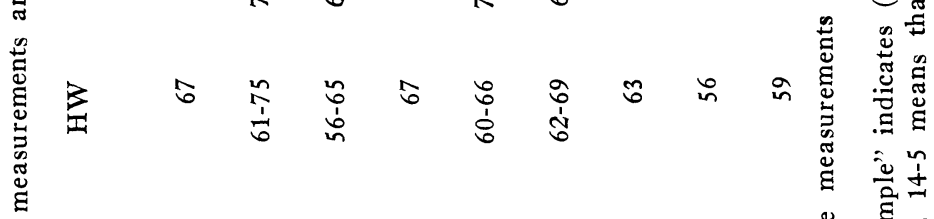

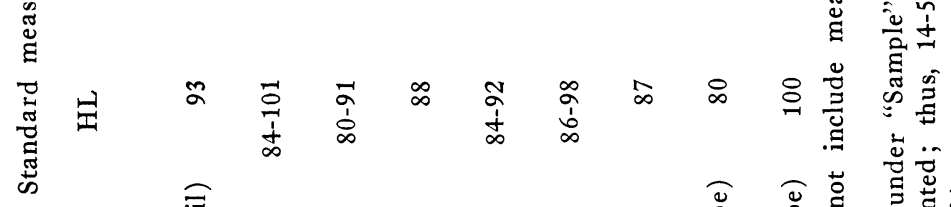

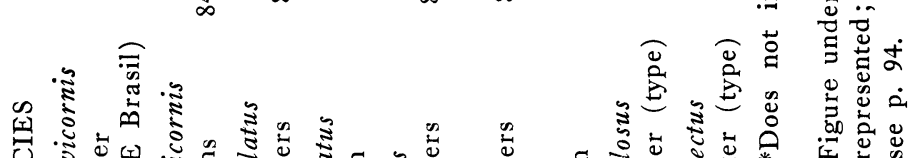

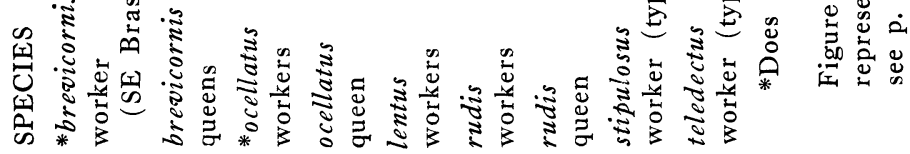


V-shaped); posterior lobes very narrowly rounded. Mandibles slender and more than $3 / 4$ the head length (see Table I), with low welts or convexities developed on their inner margins beyond midlength, but no preapical denticles. Compound eyes normally broadelliptical, only weakly convex, with about 34-45 facets, greatest diameter 0.II-0.13 mm. One (Trinidad) specimen has the left eye abnormally small (diameter $0.08 \mathrm{~mm}$, only about 9 facets), whereas the opposite eye is nearly normal in size and facet number.

The petiole is quite slender, especially as viewed from the side, and its node is a bit lower than in $A$. rudis; petiolar node widths of the available sample $(\mathrm{n}=5)$ are $0.16-0.19 \mathrm{~mm}$, modal at 0.17; while for $A$. rudis the width is $0.17-0.20 \mathrm{~mm}$, modal at 0.18 .

The fossae of the sculpture are crowded on the anterior part of the cephalic dorsum, but are mostly well-separated on the posterior half of the head, with smooth or nearly smooth, shining interspaces. The fossae themselves have broad, shining bottoms. In the Trinidad worker, the posterior fossae are more often contiguous, and longitudinal rugulae begin to appear between some of them, making transition toward the doubtfully distinct $A$. lentus. Sculpture of the truncus variable; rugulose-punctulate, with interspersed small fossae; sides of mesonotum usually smooth and shining, with scattered indistinct fossae, as is sometimes also the anterior part of the propodeal dorsum. Reticulo-punctulate sculpture of petiolar node confined to lowest parts of the sides (usually occupies most of side of node in A. rudis). Pilosity abundant on head and promesonotum, but not as abundant as in $A$. rudis. Color light to medium reddish-ferruginous, appendages lighter and more yellowish, gaster sometimes feebly infuscated.

Queen (dealate) from Belém, Brasil. Greatest diameter of compound eye $0.19 \mathrm{~mm}$; petiolar and postpetiolar nodes relatively larger than in worker from same nest (petiolar node $0.20 \mathrm{~mm}$ wide). Propodeal teeth stout, but still long and acute. Mesonotum with crowded distinct fossae, contiguous and nearly so; interspaces and fossae smooth or nearly smooth, shining; scutum and scutellum with median longitudinal carinula. Mesopleura smooth and shining, sides of pronotum rugose-fossulate, sides and dorsum of propodeum in part finely rugulose-punctulate. Otherwise differing from the worker by the usual caste characters.

Male unknown. 


\section{Assignment of THE NAME}

Acanthognathus ocellatus was described by Mayr ( 1887 ) from a single worker taken by Hetschko in "St. Catharina," southern Brasil. Since that time Acanthognathus has been collected rather frequently in southeastern Brasil, and until recently, it was assumed that all of these collections belonged to $A$. ocellatus. This assumption was based partly on the fact that the accumulating samples all clearly belonged to a single endemic southeastern species, and partly on Santschi's confident determination of 1922, by which he attached the name ocellatus to the commonly-collected species and gave a crude figure of the worker head over this name. His sample came from the vicinity of Rio de Janeiro.

Borgmeier had early doubts concerning the identity of this form, as seen from some labels on specimens in his collection that read, "Acanthognathus sp. nov." Borgmeier's opinion must have arisen when he compared his specimens of this form with Mayr's original description of $A$. ocellatus, for the match is a poor one. Mayr gives the length of the mandibles in ocellatus as $0.9 \mathrm{~mm}$, and the head length as $\mathrm{I} . \mathrm{O} \mathrm{mm}$, which yields a mandibulo-cephalic index (MI) of 90 , whereas $\mathrm{MI}$ in the common species runs from 63 to 73 in the sample available. More significant even than this is Mayr's description of the cephalic sculpture of ocellatus as, ". . . nicht dicht mit sehr grossen, kreisrunden, flachen und sehr seichten Punkten besetzt, jeder punkt hat in der Mitte eine sehr kleine kegelige Erhöhung, welche ein Haar tragt; die Zwischenraume zwischen den Punkten, wie auch die Punkte selbst sind glatt und glanzend . . ." The commonly-collected form, on the contrary, has dense, finely rugulose-punctulate, opaque sculpture within and between the numerous small circular fossae over the entire cephalic dorsum behind the eyes. It therefore seems clear that the southeastern Brasilian form called "A. ocellatus" (at least since I922) cannot belong to that species, and we here describe it as a new species, $A$. rudis (below).

The problem remained as to what the original $A$. ocellatus really was. Unfortunately, the unique type specimen is missing from the place where one would expect to find it in the Mayr Collection in Vienna, and it was presumed lost. In recent years (Kempf, I964), the rare species $A$. brevicornis has been found in the state of Rio Grande do Sul, neighboring Santa Catarina to the south. This species conforms to the ocellatus description in size and cephalic sculpture, but the promesonotum of brevicornis is smooth and shining, with a few scattered, feeble fossae, whereas Mayr described ocellatus as having "Der ganze Thorax grob und verworren gerunzelt mit eingestreuten solchen haartragenden Punkten, wie sie am Kopfe 
vorkommen." Furthermore, in brevicornis the antennal scapes do not reach the posterior margin of the head at any point, whereas according to Mayr the scapes "überragt sehr wenig die Hinterecken des Kopfes ...." in his ocellatus type. It seemed unlikely that brevicornis and ocellatus were synonymous.

Of the forms represented among the Acanthognathus samples known at the present time, there is one that agrees reasonably well with Mayr's description of ocellatus. This is the form reported under this name by Mann (I9I6) from what it now Belém, at the mouth of the Amazon. This same species is now known also from Trinidad, Panama and Costa Rica (see below), and we believe that it ranges southward from the Amazon in Brasil, but that in this area it is probably even rarer and more local than it is northward. In particular, it does not occur at the same south Brasilian localities as the apparently much more common $A$. rudis, which inhabits only subtropical wet forests on the plateaus and mountain ranges that take up much of the region. Mayr's Santa Catarina ants were sent him by the collector Hetschko, whose base was the hot lowland town of Blumenau. Thus, it seems to us likely that the main reason this species - the real ocellatus - has not been collected again in 80 years is simply that no one has collected for cryptobiotic ants in the Bluemenau area or in other suitable hot lowland localities along the south Brasilian coast.

To the above reasoning, we can now add that the type of $A$. ocellatus has finally been located. It resides, probably ever since its loan to Carlo Emery, in the Museo Civico di Storia Naturale "Giacomo Doria" in Genoa. Dott. Delfa Guiglia, First Conservator of that institution, has kindly sent us information on the critical characters of the single worker specimen; this will have to serve in place of its loan for our standard measurement and examination.

According to Dott. Guiglia's first letter, dated 8 December I968, the presumed type bears the label, "Acanthognathus ocellatus Mayr - St. Catharina." It is not labeled as type, but like us, Dott. Guiglia believes that it "is certainly the type." Her characterization, very slightly paraphrased: Dorsum of the head with large, shallowly impressed, well defined punctures, about $0.03 \mathrm{~mm}$ in diameter and papillate in the middle. Narrow spaces between these punctures smooth and rather shining, without any trace of reticulation. Anterior third of head with shallow longitudinal furrow in the middle."

The first measurements sent were mostly only taken to the nearest tenth of a millimeter, and therefore lack sufficient precision for our 
purposes. In answer to our further request, in her second letter, dated 29 December 1968, Dott. Guiglia graciously sent measurements of SL and ML taken to 4 decimal places of a millimeter. Rounded to 3 decimal places, which is nearer the limits of precision of standard stereomicroscopes, these are: SL 0.772, ML $0.755-$ dimensions close to those listed for the other samples of $A$. ocellatus and not so close to those for the known samples of $A$. brevicornis. In order to differentiate further against $A$. brevicornis, we queried Dott. Guiglia about the presence of preapical denticles on the mandibles, and she replied emphatically in her second letter that "indistinct denticles on the inner mandibular margins before the apices [do] not exist."

While we recognize the danger of not actually examining the specimen in this case, it does seem hardly likely from the weight of the evidence that the ocellatus type can belong to any species but the one to which we here attach the name.

Material examined: costa RICA: Puerto Viejo de Sarapiquí, Heredia Prov., 30 July 1965, D. H. Janzen leg., I worker (MCZ). Panama: Cerro Campana, Prov. Panamá, ca. $800 \mathrm{~m}$, i 7 Jan. I960, G. B. Fairchild and W. L. Brown, Jr. leg., $6 \mathrm{w}$ and I dealate queen with brood, from rotten twig in wet montane forest ( $\mathrm{MCZ}, \mathrm{WWK}$ and elsewhere). Barro Colorado I., Canal Zone, 9 July I956, C. W. and M. E. Rettenmeyer leg., I w, berlesate, dirt from bivouac of Eciton vagans. TRINIDAD: Simla, Arima Valley, I2 Jan. I966, H. Markl leg., I w taken "at night” (MCZ). BRASIL: Belém, Pará, I9i4, W. M. Mann leg., I w and I dealate queen (MCZ).

\section{Acanthognathus rudis $\mathrm{sp}$. nov.}

(Figs. I, 2, 4-IO)

Acanthognathus ocellatus (not of Mayr): Santschi, 1922: 353-354, fig. 2, worker from State of Rio de Janeiro, Brasil. - Borgmeier, 1927:120, record from State of Rio de Janeiro.- Kempf, 1958:553-554, record from Guararema, S. Paulo.- Brown and Wilson, 1959:282, fig. 3, worker.- Kempf, 1964:67, records from states of Rio Grande do Sul, Santa Catarina, Paraná, São Paulo and Rio de Janeiro.

Holotype worker: TL 4.2, HL 0.93, HW 0.65 (CI 70), ML o.68 (MI 73), WL o.86, petiole $\mathrm{L}$ in dorsal view 0.55 , postpetiole L 0.20 ( W 0.20 ), gaster L 0.97 , greatest diameter of compound eye O.I3, scape L (chord to basal collar) $0.76 \mathrm{~mm}$. Standard measurements of a selection of specimens from the type series are listed in Table I.

This species is so well known (under the name ocellatus) that Figs. I, 2, and 4, and the measurements and indices, plus mention 

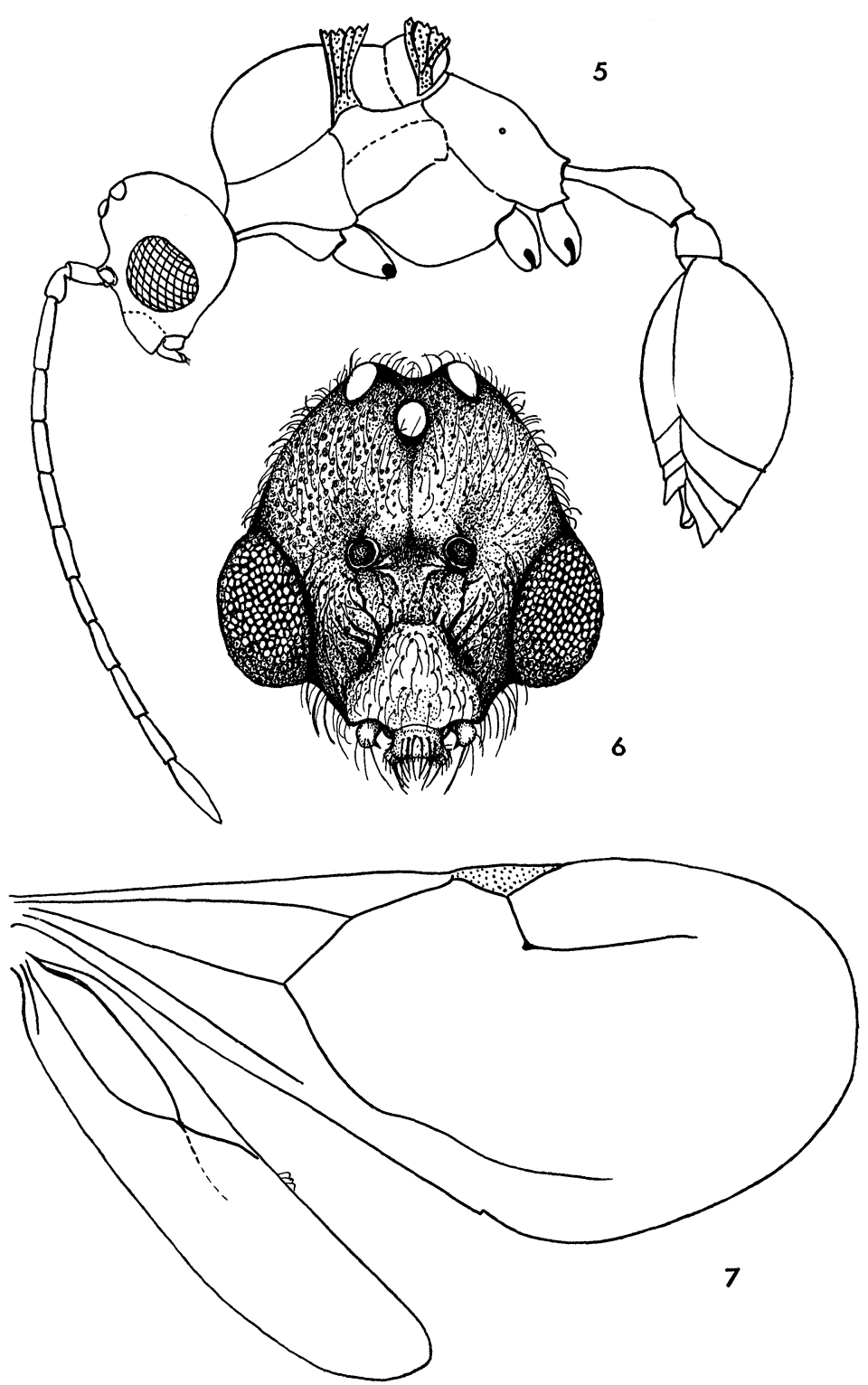

Figures 5-7. Acanthognathus rudis sp. n., male from type nest series (Agua Funda). Fig. 5, side view. Fig. 6, full-face view of head, antennae omitted. Fig. 7, wings, microtrichiae omitted. Figs. 5 and 7 drawn by Kempf, Fig. 6 by Ruth Ann DeNicola. 
of a few outstanding features, should suffice to characterize it. Note the rather V-like outline of the posterior excision of the head. Head slightly more depressed, less convex above, than in $A$. ocellatus.

The outstanding trait is the fine, nearly opaque, densely rugulosepunctulate sculpture of head and truncus. Among the rugules are crowded numerous small piligerous fossae, especially on the dorsum of the head, but these are clearly visible only in certain lights. Sides of truncus finely punctulate-rugulose, except for the lowest part of the mesothorax, which is smooth and shining. The hairs are abundant, particularly on head and promesonotum, but also present on nodes, short and inclined, slender but blunt, often feebly flattened or clavate toward their apices, those on the head directed anteriad. Pilosity otherwise as described for the genus.

Humeral angles obtuse, not strongly projecting. Propodeal teeth diverging, very feebly curved as seen from above.

The mandibles lack preapical armament, and there is not even a distinct welt at the site of the trigger hair, though a formation extending internally to the base of the hair can be seen within the transparent cuticle of the inner mandibular margin.

Petiole with a low, rounded node (Fig. 2), the lower anterior slope with a low median carina; node obout $0.22 \mathrm{~mm}$ long and o. 8 $\mathrm{mm}$ wide; postpetiole subglobular. Petiole and postpetiole densely and finely reticulo-punctulate and opaque, except for the almost completely smooth, shining nodal summits.

Color light reddish ferruginous; nodes and gaster yellowish ferruginous; but the gaster with the middle third shading into a broad brownish-red transverse band; appendages yellow to straw.

Paratype variation is slight on the whole (see Table I). Workers from Boraceia, S. Paulo State, have the upper as well as lower mesopleura largely smooth and shining. Color varies from light to medium ferruginous.

Queen: Measurements of a queen from the type locality are given in Table I. Her distinguishing specific characters correspond in the usual way to those of the worker. Mesonotum with crowded, slightly vermiculate longitudinal rugulae, interspersed with small fossae. Pronotum and propodeum transversely rugulose. Mesopleura with the upper half rugulose or smooth; lower half mostly smooth and shining.

Male from the type nest series: TL 2.8, HL 0.52, $\mathrm{HW}$ without eyes 0.45 , with eyes $0.54, \mathrm{~L}$ antenna 2.0, ML 0.05 , WL $0.90, \mathrm{~L}$ forewing $2.55 \mathrm{~mm}$. 
See Figs. 5-10. Smooth and shining, with small punctures abundant on head, a few rugae around the antennal insertions. Mesonotum finely and indistinctly longitudinally striolate-punctulate, sericeous-opaque. Color brown to piceous, head darkest (specimens may not be fully colored). Legs and mouthparts yellowish-tan.

Type material: all from Brasil; states are given in capital letters. Holotype (WWK) a worker from a small nest with queen and brood taken in a fragment of rotten wood found lying beside a brook in a moist, shaded gully in the forest reserve of the Jardim Botanico, environs of the city of São Paulo, SAO PaUlo, February 1967, W. L. Brown leg. This colony was kept for observation, and eventually yielded two adult males, the only ones so far recorded for the genus. Paratypes, in addition to workers, queen and males from the type nest (MCZ, WWK), are the following (states listed south to north): RIO GRANDE DO SUL: Tainhas, April I959, F. Plaumann leg., I w[orker] (WWK 3250). SANTA CATARINA (all Plaumann leg.): Chapecó, June, August 1960, 2W (WWK s/n and 4618); Ibicaré, July 1959, I q(ueen) (WWK 3126) and September 1960, 2 w, (WWK 362I) ; Nova Teutonia, July 1952 2 w, October 19532 w I q, June I957 I w 2 q, July 1957 I q, February I959 I w, July I959 I W (WWK 3100 ); February I960 I w (WWK 3780), June I960 I w (WWK 3956); July ig6 I I w (WWK 3379); January I963 I w (WWK 3744); June I963 I w

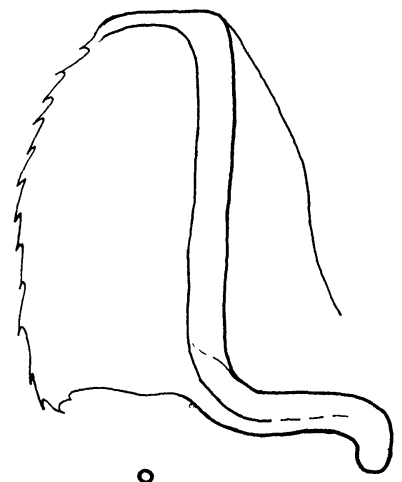

8

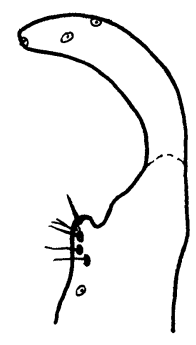

9

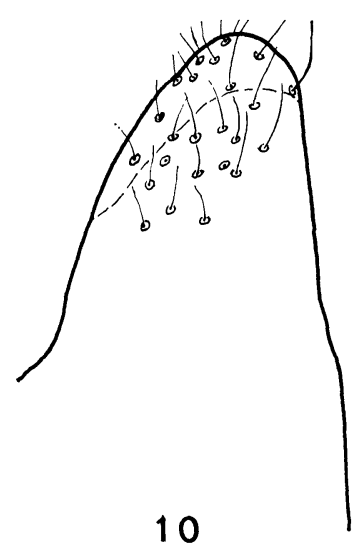

10

Figures 8-10. Acanthognathus rudis sp. n., male genitalia from one of the specimens from the type nest series. Fig. 8, aedeagus. Fig. 9, volsella. Fig. 10, paramere, with dashed line indicating apical extremity of excavated portion. Drawn by Brown. 
I q (WWK 3709); Seara, July I958 3 w (WWK 2687). PARANÁ: Bocaiuva, May ig63, F. Plaumann leg. 2 w (WWK 3999) ; Palmeira, May I964, F. Plaumann leg. I w (WWK 40I 5 ); Volta Grande, April 1949, Hertel leg. 5 w (MCZ, WWK). SAO Paulo: Barueri, December 1958, K. Lenko leg. 8 w (No. 708); Guararema, December i957, W. W. Kempf leg., i I w, i q (WWK 2 I02, MCZ, Cornell); Jardim Botanico, Agua Funda, São Paulo, September 1958, K. Lenko leg. 8 w (No. 608); August 1962, and February 1967, W. L. Brown leg. 4 nests and partial nests from rotten wood, workers, queens and males ( $\mathrm{MCZ}, \mathrm{WWK}$ and elsewhere) ; Serra da Cantareira, cavity in small stump, with Pheidole sp., January 1959, W. W. Kempf and Vitor dos Santos leg., 4 W, I q (WWK 2915). Boraceia, Municipio de Salesopolis, February I967, nest in rotten twig in litter, R. H. Crozier leg. $4 \mathrm{w}$ (MCZ) RIO DE JANeIRo: Parque Nacional do Itatiaia, December I955, T. Borgmeier leg. I w.

\section{Acanthognathus stipulosus sp. nov.}

(Fig. 3)

Holotype worker: Measurements and indices given in Table I. A small-sized, slender species resembling $A$. ocellatus and $A$. brevicornis.

The character that immediately sets this species off from the rest is the shape of its petiole (Fig. 3). Set on a long, gently curved peduncle, the node is compressed anteroventrally, and is sharply rounded above in side-view profile. Seen from above, the anterior peduncle is about $3 \frac{1}{2}$ times as long as the node, and the posterior peduncle about half as long; the node itself is about $0.10 \mathrm{~mm}$ long and $0.18 \mathrm{~mm}$ wide, with a convex anterior face and a flat, sloping posterior face; the anterior peduncle widens gradually behind the spiracles to receive the node. Seen from behind, the node is somewhat like a Formica petiole in outline, with broadly rounded crest, bulging sides and narrower ventral portion. Postpetiole about 0.I6 $\mathrm{mm}$ long, $0.17 \mathrm{~mm}$ wide, subcircular as seen from above, with straight anterior margin.

Also the following characters:

( I) Mandibles relatively shorter than in ocellatus, their preapical borders unarmed except for an almost imperceptible "submedian welt."

(2) Humeral teeth triangular, strongly projecting, rendering the promesonotum very slightly broader than long (cervix excluded). 
Sculpture of promesonotum consisting of about 8 slightly wavy costulae running anteriad from the metanotal groove and fanning out to meet 2-3 short transverse costulae on the anterior pronotum; costulae and interspaces shining; cervix smooth and shining.

(3) Propodeal dorsum gently convex, smooth and shining discad; spines long and nearly straight as seen from side, but slightly divergent with apices incurved as seen from above; moderately elevated.

(4) Head smooth and shining, with spaced but large and distinct round fossae over the dorsum, each centrally tuberculate and bearing an inclined, short, white clavate hair. Sides of alitrunk loosely rugose, shining; rest of body and most parts of appendages smooth and shining.

(5) Color reddish ferruginous, gaster darker, reddish-brown; legs, mandibles and antennae pale straw yellow, middle and posterior femora each with a broad subapical brownish band.

Holotype (MCZ) a unique taken in rain forest near the quarry at the high falls (Cachoeira Alta) of a branch of the Rio Tarumã, northeast of Manaus, Amazonas, Brasil; 28 August 1962, W. L. Brown, Jr., leg. The worker was taken from a leaf litter berlesate.

This is the first record of the genus from the middle Amazonian region. It must be uncommon, for it was taken only once out of many Berlese funnel extractions from the Manaus area.

\section{Acanthognathus teledectus sp. nov.}

(Fig. I I)

Holotype worker: Measurements and indices in Table I. A large species, distinguished by the very narrow head and extremely long mandibles. In addition, the following character states:

I. Each mandible with 2 long and I short spiniform preapical teeth, also a well developed convex lamelliform welt beyond midlength, giving rise to a fine erectile trigger hair.

2. Clypeus very narrow.

3. Alitrunk slender, humeral angles low, obtuse, not strongly projecting. Propodeal dorsum flat; spines approximately straight, only slightly diverging, not quite as long as the distance between the centers of their bases, only slightly elevated.

Petiole and postpetiole formed much as in rudis, but relatively more slender (petiolar node $0.16 \mathrm{~mm}$ wide); node as seen from above oval, slightly longer than broad, and about half as long as its anterior peduncle. Postpetiole about $0.19 \mathrm{~mm}$ long and $0.18 \mathrm{~mm}$ wide, narrower anteriad. 
106

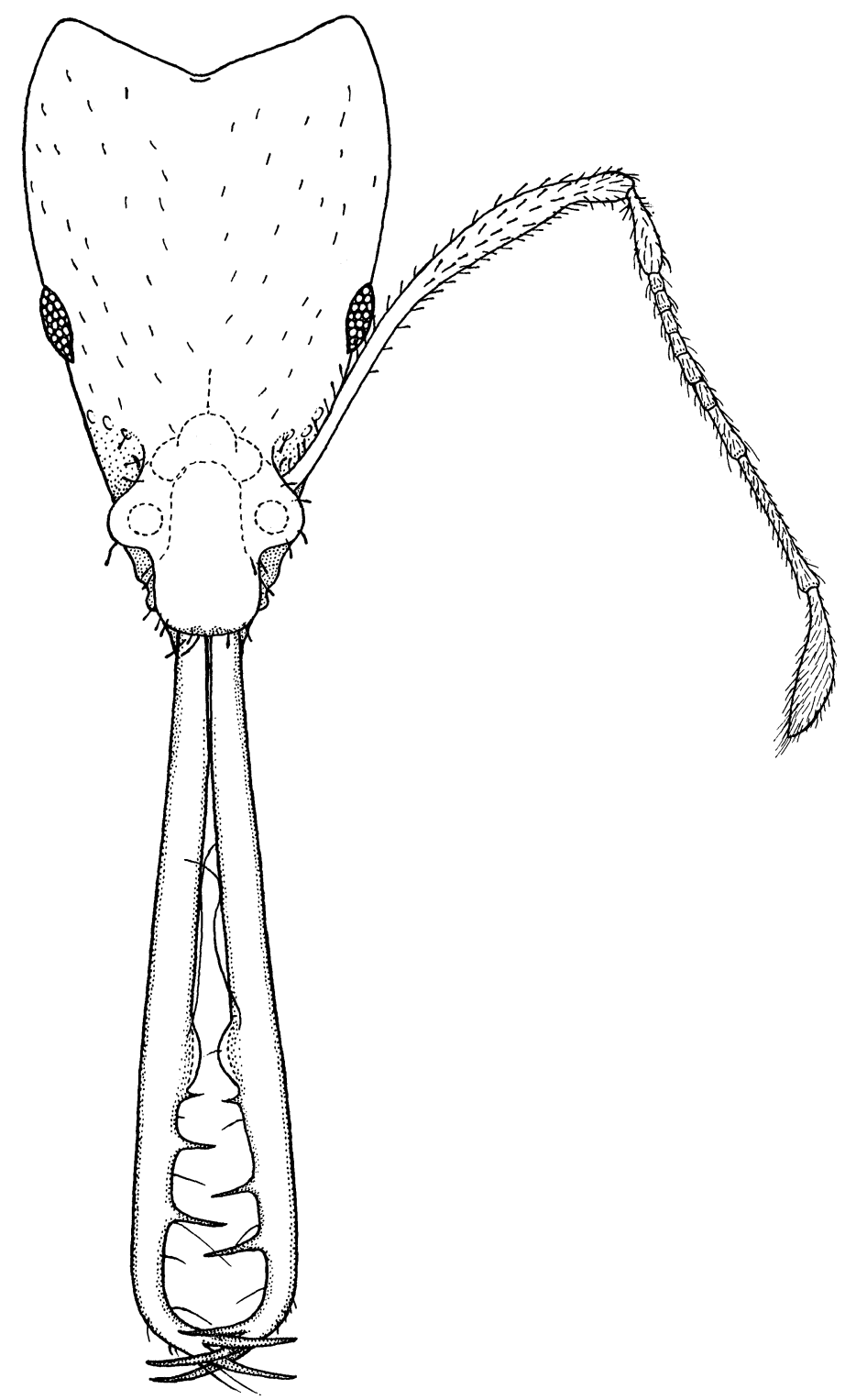

Figure 11. Acanthognathus teledectus sp. n., holotype worker (Bajo Calima, Colombia), dorsal view of head with mandibles and left antenna. Drawn by Margaret Menadue. 
5. Body prevailing smooth and shining. A few indistinct fossae persist on anterior part of head, especially in the region in front of the eyes. Parts of lower sides of alitrunk, also petiolar peduncles in front and behind minutely and densely punctulate.

6. Clavate pilosity very sparse on clypeus, cheeks, mandibles, upper vertex, humeral angles, spines and posterior faces of both nodes, and more abundant on antennal scapes, legs and underside of head.

Color light ferruginous; antennae, legs and gaster lighter, more yellowish.

Holotype (MCZ) a unique taken in lowland rain forest on the property of Carton de Colombia (a paper-manufacturing firm) in Bajo Calima, Municipio de Buenaventura, Departamento de Valle, Colombia. The collection was made near the then principal logging road on I6 March I967, at Kilometer Io northward from the company's headquarters, R. B. Root and W. L. Brown, Jr., leg. The specimen was found, alive and with the incredible mandibles opened to approximately $\mathrm{I} 8 \mathrm{O}^{\circ}$, in thin humus immediately below a layer of leaf litter I $\mathrm{cm}$. thick. No more specimens could be found in the vicinity.

This is the first member of the genus found in trans-Andean South America. The extremely long, heavily-armed mandibles and smooth integument distinguish it at once from the other known species.

Key to the Species of Acanthognathus, Based on Workers and Females

I. Mandibles decidedly longer than head proper, each with 2 or 3 long spiniform teeth before the apex (Fig. II); dorsum of head smooth and shining (Colombia: Pacific lowlands)

teledectus

Mandibles not longer than head proper, preapical inner borders unarmed, or at most with low irregular denticles and/or welts (Fig. I) ; dorsum of head sculptured, at least with numerous distinct round fossae on the disc, intervals smooth or rugulose

2. Petiole with very long, slender peduncle, about $3 \times$ as long as its node, which is short and transverse as seen from above (Fig 3; Amazonia: near Manaus) stipulosus Petiolar peduncle slender, but less than twice as long as its node, which is oval and at least as long as broad as seen from above (Fig. 2) 
3. Antennal scapes short, chord less than $90 \%$ as long as manidibles seen in dorsal view; preapical area of inner mandibular border with (usually 2 or more) irregular denticles (Panama and Brasil: Para and Rio Grande do Sul) .............. brevicornis Antennal scapes with chord about as long as, to much longer than, the mandibles as seen in dorsal view; inner mandibular borders without preapical denticles, though a submedian welt may be present 4 .

4. Mandibles shorter (MI 60-75; Figs. I, 4); dorsum of head completely, densely and rather finely rugulose, with interspersed fossae numerous, small and crowded, so that the surface, including the area around the eyes, is essentially opaque (SE Brasil, fairly common in wet forest in plateaux and uplands) rudis

Mandibles longer $(\mathrm{MI}>75)$; dorsum of head loosely sculptured and more or less shining, fossae large and shallow, with smooth spaces or simple longitudinal rugulae between some rows; at least a strip bordering each eye mesially nearly smooth, shining

5. Fossae on posterior half of dorsum of head smaller, mostly separated by flat, smooth spaces (Central America, Trinidad and southward locally in Brasilian lowlands to S. Catarina)

ocellatus

Fossae on posterior half of dorsum or head large, mostly contiguous or separated by single, simple longitudinal rugulae (Honduras; may be only a coarsely-sculptured variant of ocellatus)

lentus

\section{Acknowledgements}

We are grateful for assistance that made this study possible. Brown was aided by U. S. National Science Foundation Grants G-2368o, GB-2I 75 and GB-5574; Kempf received support from the Conselho Nacional de Pesquisas do Brasil. Dott. Delfa Guiglia gave us information on the type of $A$. ocellatus, and various collectors, listed under each species treatment, have sent us their valuable samples. Dr. Howard E. Evans (MCZ) has taken the trouble to mail us loans of material. 
BORGMEIER, $T$.

\section{References Cited}

1927. Algumas novas formigas brasileiras. Arch. Mus. Nac., Rio de Janeiro, 29: 57-65.

Brown, W. L., JR.

1948. A preliminary generic revision of the higher Dacetini (Hymenoptera: Formicidae). Trans. Amer. Entomol. Soc., 74: 101-129.

Brown, W. L., Jr. and E. O. Wilson

1959. The evolution of the dacetine ants. Quart. Rev. Biol., 34: 278-294. EMERY, C.

1922. Hymenoptera, fam. Formicidae, subfam. Myrmicinae. Genera Insectorum, Brussels, 174C: cf. p. 317-318.

KEMPF, W. W.

1958. The ants of the tribe Dacetini in the state of São Paulo, Brazil, with the description of a new species of Strumigenys (Hymenoptera: Formicidae). Studia Entomol., (n. s.) 1: 553-560.

1964. Miscellaneous studies on Neotropical ants. III. (Hymenoptera, Formicidae). Studia Entomol., (n. s.) 7: 45-71.

ManN, W. M.

1916. The Stanford Expedition to Brazil, 1911, John C. Branner, Director. The ants of Brazil. Bull. Mus. Comp. Zool., Harv., 60: 397-490, pl. 1-7.

1922. Ants from Honduras and Guatemala. Proc. U. S. Nat. Mus., MAYR, G. $61(13): 1-54$.

1887. Südamerikanische Formiciden. Verhandl. Zool.-bot. Ges. Wien, 37: 509-631 (cf. p. 578-579).

SANTSCHI, F.

1922. Myrmicines, dolichodérines et autres formicides néotropiques. Bull. Soc. Vaudoise Sci. Natur., 54: 345-378.

SмITH, M. R.

1944. A key to the genus Acanthognathus Mayr, with the description of a new species. Proc. Entomol. Soc. Wash., 46: 150-152.

WILSON, E. O.

1962. Behavior of Daceton armigerum (Latreille) with a classification of self-grooming movements in ants. Bull. Mus. Comp. Zool., Harv., 127: 401-421. 

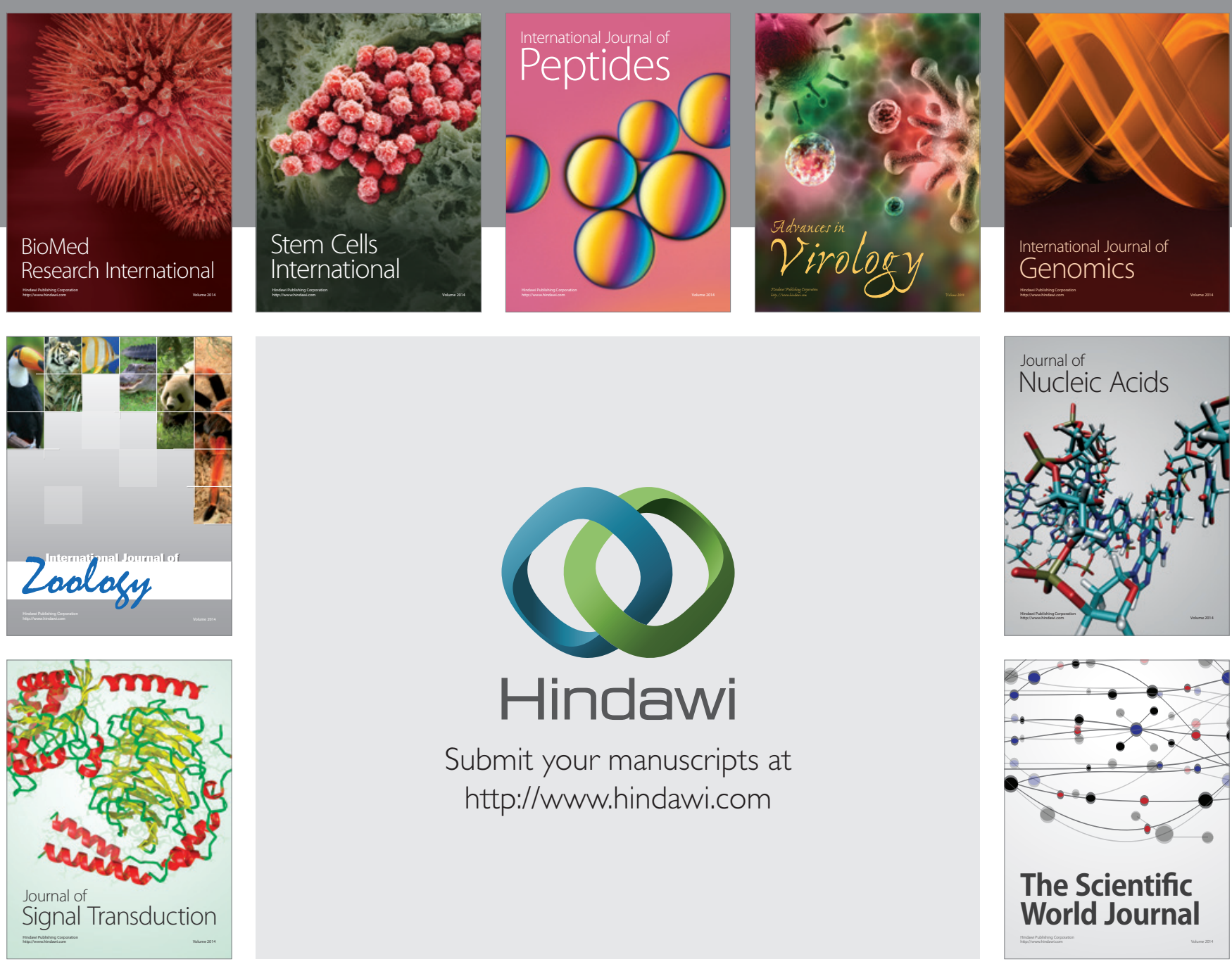

Submit your manuscripts at

http://www.hindawi.com
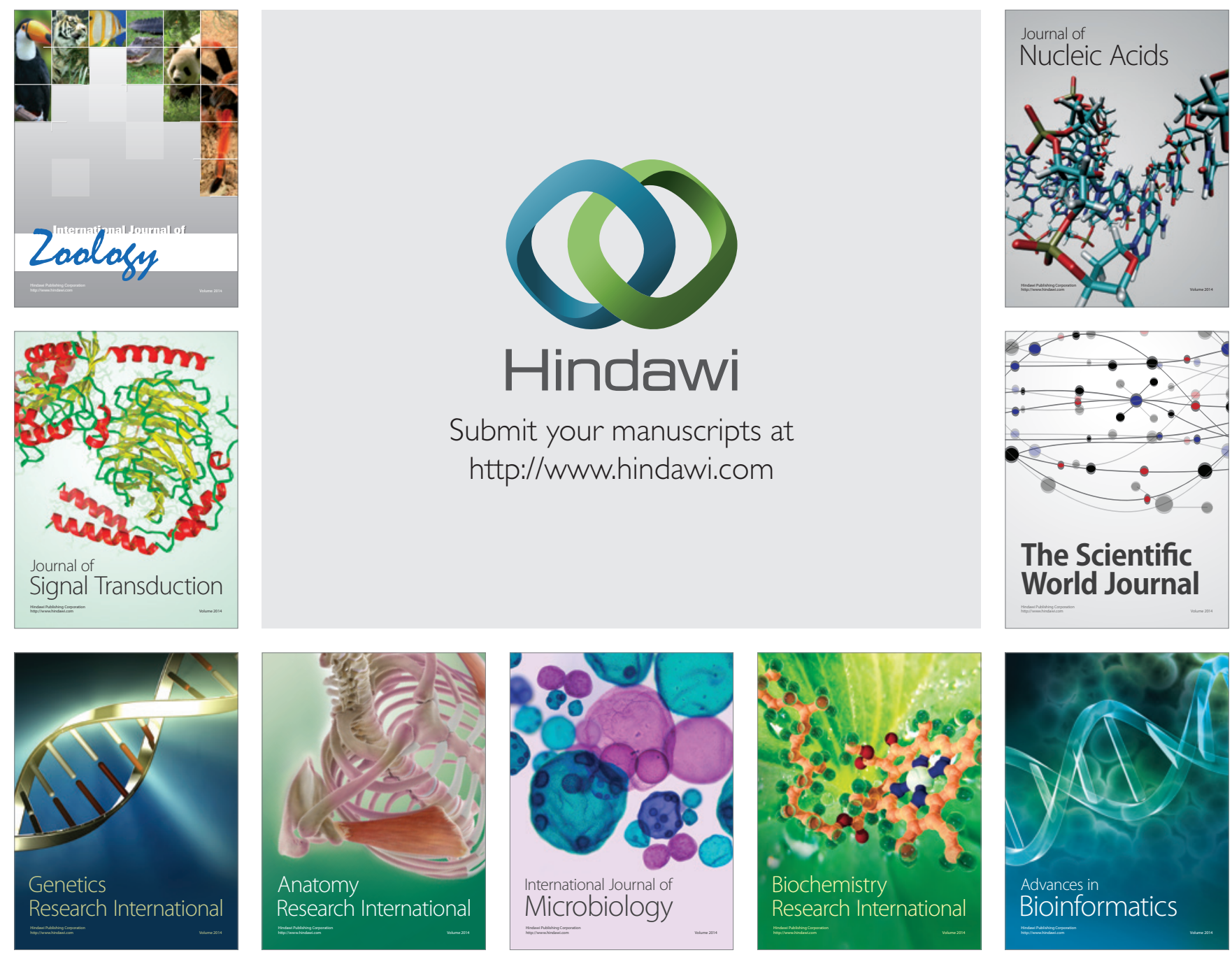

The Scientific World Journal
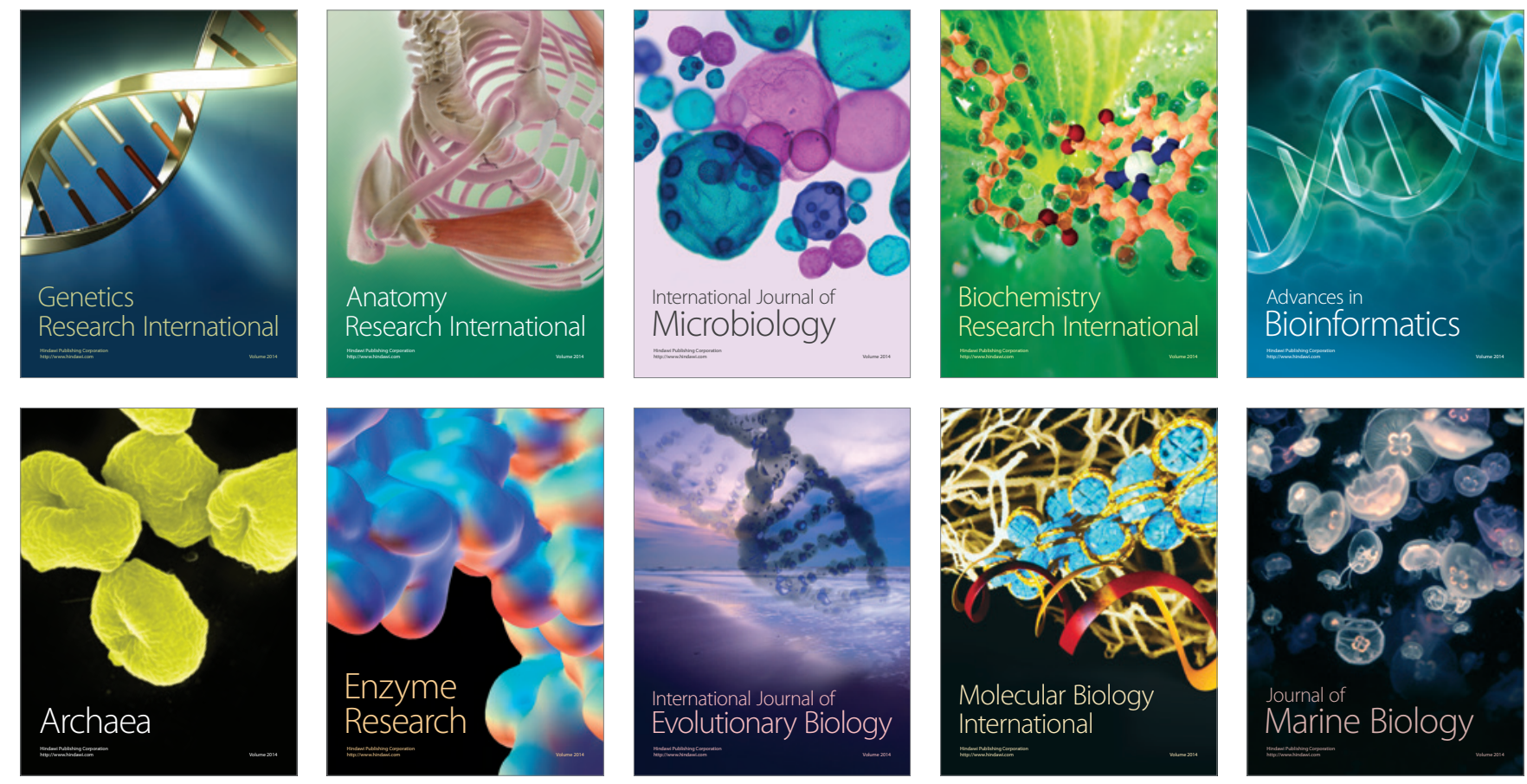